\title{
О.И. Целищева
}

\section{КОНФЛИКТ НОРМ В ФИЛОСОФСКОМ МЫШЛЕНИИ: СЛУЧАЙ АНАЛИТИЧЕСКОЙ ФИЛОСОФИИ}

\begin{abstract}
Рассмотрена проблема конфликта норм в философском мышлении в рамках одной парадигмы. Предметом анализа были выбраны стили мышления в современной аналитической философии в трактовке восходящего к Аристотелю тезиса эссенцииализма о наличии у объектов необходимых и случайных свойств. Исследуется конфликт между антиметафизической трактовкой эссенциилизма У. Куайном и возрождением метафизики эссенциализма С. Крипке. В статье делается вывод, согласно которому история неприятия и возрождения в аналитической философии аристотелевского эссенциализма представляет собой изменение концепции нормативности.

Ключевые слова: норма, парадигма, эссенциализм, метафизика, Хинтикка, Куайн, Крипке, Рорти.
\end{abstract}

Каждой философской школе присущи свои способы обсуждения и решения проблем. При всех разговорах о Философском Методе, подразумевающих неявно единственность такого метода и его отличие от научных методов, различия в таких способах являются настолько существенными, что неприятие философскими направлениями друг друга доходит до полного отрицания принадлежности соперника к философии вообще. Однако внутри каждой из конфликтующих школ существуют значительные разногласия по множеству вопросов. Такое положение дел ставит под сомнение саму идею особого философского метода. С другой стороны, вполне возможно, что упомянутые противоречия между методами различных философских направлений являются преувеличением, поскольку зачастую можно говорить о том, что противники в философии охотно заимствуют проблематику друг у друга и разделяют некоторые базисные предпосылки.

В данной статье рассматривается случай аналитической философии, которая, по общему убеждению, противоположна так называемой континентальной философии во многих отношениях, по крайней мере в отношении метафизики. Со времени критики Б. Расселом и Дж. Муром британского абсолютного идеализма и исключения метафизики из философии Венским Кружком метафизические темы долгое время не приветствовались в аналитической философии. Однако начиная с 1980-х гг. можно говорить о нарушении этого табу, проявившемся в успешном применении модальной логики к анализу метафизических контекстов. В самое последнее время возник интерес к таким темам, как аналитическая эстетика или аналитическая теология. В определенном смысле это явилось нарушением признанных норм философствования в аналитической философии. Представляет интерес рассмотрение этого феномена с двух разных точек зрения - континентальной и аналитической. В качестве представителя первой нами выбран известный критик аналитической философии прагматист Ричард Рорти, а представителем второго - ведущий логик и философ науки Я. Хинтикка. Предметом их оценки 
является обоснованность попыток возрождения метафизической доктрины эссенциализма одним из наиболее известных аналитических философов С. Крипке. Для понимания ситуации следует сделать некоторый экскурс в соотношении логики и философии.

Б. Рассел полагал, что в основе метафизических систем лежат, явно или неявно, логические доктрины, провозгласив знаменитый лозунг «Логика есть сущность философии», который определил этим самым важную составляющую аналитической философии. Убедительным примером такой стратегии является выделение Расселом «доктрины внутренних отношений», лежащей в основе метафизики Ф. Брэдли, и провозглашение «доктрины внешних отношений», требуемой для новой философии логики и математики, положенной в основу аналитической традиции [1]. Дальнейший «лингвистический поворот» обобщил эту тенденцию, расширив роль, предназначавшуюся логике, до анализа языка вообще, поставив в центр внимания анализ значения [2]. Наконец, усилиями Венского Кружка аналитическая философия окончательно сориентировалась на научный способ обсуждения своих проблем. В частности, атака на метафизику увенчалась убеждением, что утверждения, не являющиеся эмпирически проверяемыми, являются попросту бессмысленными. К осмысленным, но неинформативным, относились математические и логические утверждения. Антиметафизическая направленность явно стала считаться нормой аналитического способа философствования. Таким образом, логика и лингвистический анализ стали играть ведущую роль в формировании аргументов против метафизики как допустимого метода в философии.

Однако дальнейшее развитие логики привело к тому, что сама логика стала неявной поддержкой метафизики. В частности, речь идет об эссенциализме Аристотеля. Модальная логика апеллирует к метафизическим концепциям необходимого и случайного утверждений. Эссенциализм как доктрина резко контрастирует с эмпиризмом как неотьемлемой частью аналитической традиции. Для сохранения последней в чистоте роль экзорциста взял на себя виднейший логик и, пожалуй, наиболее видный аналитический философ второй половины XX в. У. Куайн. Будучи сторонником тотального проникновения эмпиризма в философию в виде так называемой натурализованной эпистемологии, Куайн в своей критике метафизики сделал вполне обоснованный шаг, приведя аргументы против возможности кванторной модальной логики [3]. Именно в языке этой логики возможна строгая формулировка понятий необходимости и возможности, по крайней мере так называемой алетической модальности. Больше того, именно в этом языке находят точное выражение понятия de re и de dicto модальностей, употребление которых было важным в аристотелевского толка метафизике. Куайн представил аргументацию, согласно которой квантификация модальных контекстов ведет к аристотелевскому эссенциализму, который считался им попросту недопустимым в научно ориентированной философии. Эти аргументы сводились в представлению им в кванторной модальной логике парадоксов, разрешение которых не представлялось легким делом.

Конечно же, речь не идет о том, что с помощью логики Куайн опроверг эссенциализм как метафизическую доктрину; на самом деле он отвергает ее изначально. Речь идет о том, что в основу метафизики необходимости и возможности нельзя класть логику. Лишение логики статуса верховного судьи в 
этом вопросе сильнейшим образом подрывает саму идею аналитического метода. Парадоксы кванторной модальной логики Куайна породили значительную вторичную литературу, цель которой состояла в попытках ограничения значимости куайновской аргументации. В частности, речь шла о степенях вовлечения кванторной модальной логики в эссенциализм. Некоторые степени такого вовлечения оказались достаточно невинными, и тем не менее окончательно избавиться от парадоксов не удавалось. Дело в том, что парадоксы намекали на формальные дефекты самой кванторной модальной логики. Далеко не все аналитические философы были согласны с тем, что узкие технические вопросы логики должны иметь такое решающее значение для философии как таковой. Параллельно с их сомнениями шли активные поиски удовлетворительной в формальном отношении системы кванторной модальной логики. Иронией судьбы во всей этой истории является то, что корректность данной логики была показана не кем иным, как аспирантом Куайна, впоследствии известным философом Д. Феллесдалем. Любопытным обстоятельством является и то, что впоследствии Д. Феллесдаль много усилий приложил для установления связей аналитической философии и феноменологии.

Но реакции Куайна практически не последовало, что подтверждало точку зрения тех, кто не видел прямой связи между логикой и метафизикой. Дело в том, что позиция Куайна в отношении метафизики определялась не столько частными техническими проблемами кванторной модальной логики, сколько его более общей эмпиристской позицией, в которой не было места концепции значения как интенсиональной сущности. Его работа 1951 г. в этом направлении «Две догмы эмпиризма» [4] сделала его доминирующей фигурой в аналитическом движении. Сама идея «необходимой истины», важнейшей категории в доктрине эссенциализма, оказалась под вопросом. В этом отношении Куайн унаследовал традицию, идущую от Фреге и Рассела, согласно которым полагание одних свойств необходимыми, а других случайными - это просто наследие схоластики средневековой схоластики, восходящей к Аристотелю. Куайн убедительно показал, что необходимость и случайность на самом деле зависят от способа описания или указания объекта, обладающего этими свойствами. Таким образом, указание объекта определяется значением, потому что описание создает в определенном смысле объект.

В этом смысле история неприятия и возрождения в аналитической философии аристотелевского эссенциализма представляет собой изменение концепции нормативности как некоторого рода предписания, что можно там делать, а что нельзя. Неизбежно соотнесение изменения норм с переходом к одной парадигмы к другой. Но, на наш взгляд, было бы естественным считать изменение норм процессом в рамках одной парадигмы, процессом в рамках нормального периода развития науки. Но и при этом исследование такого процесса является важным для понимания структуры философского мышления.

Таков фон, на котором развернулось сражение за изменение норм. Появление работы С. Крипке «Именование и необходимость» [5] стало шоком для философов, которые придерживались точки зрения Фреге-Рассела-Куайна на метафизику, в частности на эссенциализм. Вряд ли эмпирически настроенные философы были готовы принять идею, что некоторые свойства внутренне 
присущи вещам. Конструкции этих философов отвергали наивный реализм, утверждая, что указание и значение есть ментальные конструкции, не отвечающие прямо объектам внешнего мира. Аристотель в своем эссенциализме взывал как раз к такому наивному реализму, который присущ также обычному человеку и ученому. Оба они верят, что язык есть инструмент описания объектов, а не создания их. Технически Крипке представил концепцию, которая апеллировала к семантике возможных миров, т.е. в конечном счете к той самой кванторной модальной логике. В частности, он ввел понятие «твердого десигнатора», т.е. термина, который указывает на один и тот же объект во всех возможных мирах. Это означает, что указание на объект этим термином не зависит от значения термина, в полном противоречии с концепцией указания как Фреге, так и Рассела. Но в этом противостоянии есть нюанс, который превратился в своего рода идеологическое противоборство: интуиция против логической техники. Теория указания Рассела опиралась на его теорию дескрипций, которая стала частью машинерии в основаниях математики. Столь же изощренные средства использовал Фреге в своей теории смысла и указания. А вот Крипке, от которого как от автора семантики для модальной логики можно было ожидать как раз технических средств для обоснования концепции твердого десигнатора, апеллировал к интуиции, которая, с его точки зрения, обосновывала эту концепцию. Понятие твердого десигнатора и его роль в оправдании доктрины эссенциализма вызвала лавину вторичной литературы, анализ которой не предполагается в данной статье. Интерес представляет неожиданно одинаковая реакция на такое изменение норм двух антагонистов - Я. Хинтикки и Р. Рорти.

Некоторые философы считают, что появление работы Крипке «Именование и необходимость» стало новой страницей в аналитическом движении. В чем состояла важность этой работы Крипке в общефилософском контексте? Одно из достижений Крипке в опоре на интуицию обыденного человека состояло в обнаружении необходимых апостериорных утверждений, которые не допускались прежней аналитической философией. Здесь интересно мнение Рорти по поводу важности этой находки Крипке: «Мое собственное мнение об открытии необходимых апостериорных утверждений сводится к тому, что не имеет такого уж большого значения, да и не будет, вероятно, иметь. Я не вижу никаких свидетельств, что аналитические философы используют другие „фундаментальные методологические понятия“ по сравнению с теми, которые использовались ими до 1970 г. Мое впечатление, что спустя 35 лет после революции Крипке множество философов могли бы сказать ему: „Мы видели вашу точку зрения об аристотелевской интуиции обыденного человека, и готовы вслед за вами назвать необходимыми истинами „Вода есть $\mathrm{H}_{2} \mathrm{O}^{\text {“ }}$ и „Киты это не рыбы“. Мы отрекаемся от веры в том, что необходимость есть все что угодно, но только не аналитичность. Ну и что с того? Что отсюда следует? Что вы сделали, кроме как изменили наше употребление термина „необходимость“, так это сделали его немного менее парадоксальным“» [6. P. 12].

Причина скепсиса подобного рода состоит в том, что апелляция к интуиции не всегда оправдана. Поскольку Крипке был известен фундаментальными результатами в области модальной логики (изобретя семантику для формальных систем модальной логики одновременно и независимо от 
аналогичных работ Я. Хинтикки и С. Кангера), ожидания публики, что Крипке, вооруженный новой логической техникой, будет использовать ее для своей аргументации, не оправдались. Крипке в качестве «верховного судьи» в философской аргументации выбрал не логику, а «интуицию» обыденного человека. По мнению Р. Рорти, обычной стратегией Крипке стал не поиск сногсшибательных аргументов, а «интуитивность», противостоящая всяким там ложным ухищрениям различных философских школ. Как выразился Р. Рорти, после появления труда «Именование и необходимость» Крипке, обещавшего новую эру в аналитической философии, все ждали, «когда Крипке бросит следующий башмак в стену».

«Часто в литературе предполагается, что хотя за понятием необходимости может лежать некоторого интуиция... это понятие (различие между необходимыми и случайными свойствами) есть просто доктрина, придуманная каким-то плохим философом, который (я полагаю) не понимал, что есть несколько способов указания на одну и ту же вещь... весьма далеко от истины представление (что свойство может быть существенным или случайным для объекта независимо от его описания). Не имеет интуитивного содержания, которое ничего не значит для обычного человека. Предположим, кто-то говорит, указывая на Никсона, „это парень, который мог бы проиграть выборы“. Кто-то еще другой говорит, „о нет, если вы описываете его как истинно победителя, тогда не истинно, что мог бы проиграть“. Ну и кто из них философ, не-интуитивный человек? Для меня ясно, что это второй. Этот второй имеет философскую теорию. Первый человек мог бы сказать, с большим убеждением: „Ну, конечно, победитель в выборах мог бы быть кем-то еще...“ Поэтому такие термины, как „победитель“ или „проигравший“, не обозначают один и тот же объект во всех возможных мирах. С другой стороны, термин „Никсон“ есть просто имя этого человека» [7. Р. 3].

Но обладает ли обычный человек достаточной компетенцией, которая позволит ему на самом деле анализировать логику контрфактических ситуаций? На техническом жаргоне семантики возможных миров эта ситуация связана с прослеживанием индивидов сквозь возможные миры, и эти индивиды у Крипке являются как раз твердыми десигнаторами. В какой степени правдоподобно предположение, что обычный человек имеет прямую интуицию «твердости» имен, или десигнаторов? Такие ситуации связаны с тонким философским анализом, выливающимся во многие противоречащие друг другу концепции обозначения. По сути, вся западная эпистемология связана с проблемой обозначения терминами языка объектов внешнего мира и, как следствие, с проблемой того, какие термины могут быть адекватны для этой функции и как они это делают. На первом месте стоит, конечно, проблема собственных имен: есть теория Дж.С. Милля, есть теория Г. Фреге, есть теория Рассела и теперь уже теория С. Крипке. И трудно поверить, что обычный человек компетентен в выборе между этими теориями.

Таким образом, с точки зрения Рорти, существует значительный зазор между тем, что Крипке считает интуицией обыденного человека, и более реалистическим представлением об этом человеке, интуиция которого вряд ли выдержит сопоставление с философскими тонкостями, окружающими теории именования. В конце концов можно представить себе затруднения, в которые может попасть обыденный человек со своей интуицией при осмыслении си- 
туаций, хотя и в некотором отношении искусственных, но не в большей степени, чем это он делает у Крипке. Рорти приводит такой пример: «Представим себе что имя „Аристотель““ принадлежит переписчику всех произведений, которые составляют корпус сочинений, приписываемый настоящему Аристотелю. Каждый трактат в этом корпусе написан кем-то из окружения Аристотеля, а некоторые даже им самим. А теперь посмотрим, как среагирует обычный человек, вооруженный своей интуицией, на вопрос об истинностном значении предложения „Аристотель менее религиозен, чем Платон“» [7. P. 3].

Ясно, что тут требуется тонкий анализ, и опираться просто на интуицию будет опрометчиво. Но даже если оставить в стороне такие казусные случаи, возникает вопрос, решает ли что-либо интуиция в нашем выборе между, скажем, Аристотелем и Платоном? Так вот Крипке явился первым, по сути, аналитическим философом, который посчитал эссенциализм верной доктриной, реабилитируя Аристотеля, и, естественно, веру обычного человека. Что касается такой веры, то ясно, что она обязана интуиции, близко граничащей со здравым смыслом. Традиционно философы полагали такие веры наивными, не заслуживающими внимания, поскольку эти веры не являлись частью изощренных философских конструкций. Вопрос о том, в какой мере философы должны учитывать интуиции подобно рода, не пользовался особым успехом у них, пока Крипке не сделал его актуальным, провозгласив, что размышления философов в конечном счете основаны на такой интуиции, которая представляет собой до-философский дискурс.

Таким образом, важность позиции Крипке, отвлекаясь от частного случая модальной логики, заключается в том, что в основе всякой философской теоретической аргументации лежат до-философские, до-теоретические представления, которые надо учитывать, а в некотором случае ставить во главу угла, в утонченных философских конструкциях.

Следует предположить, что для обычного человека с его интуитивными представлениями вопрос о том, чья теория - Крипке или Рассела - более предпочтительна, глубоко безразличен. И вряд ли имеет смысл полагаться на интуицию обычного человека в такого рода вопросах. Но даже если мы не будем утрировать ситуацию обращением к фигуре обычного человека вместо понимания места этих дебатов в общей культуре, ясно, что следствия семантических теорий указания вряд ли окажут какое-либо влияние на культуру в целом. Для Рорти, если мы говорим о философии вообще, является важным положение о том, что философия является частью культуры, и такие технические вопросы, как роль логических концепций в философских взглядах, вряд ли что-либо меняют в оценке роли философии в культуре. Однако столь общая постановка вопроса нивелирует вообще вопрос о специфике философского метода, наличие которого Рорти отрицает полностью.

С другой стороны, если мы не хотим остановиться на уровне «обычный человек vis a vis культура в целом», нас прежде всего интересует философская позиция в отношении уже философской интуиции, облагороженной средствами философии интуиции обычного человека. С этой точки зрения чрезвычайно интересна точка зрения соперника Крипке по изобретению семантики для модальной логики, Я. Хинтикки. Он резко критикует понимание задачи философии как систематизации интуиций философа относительно 
исследуемого предмета. В определенной мере такие интуиции весьма близки к до-философской интуиции.

«Я нахожу подобную практику скандальной. В прошлом каждый видный философ, который взывал к интуиции, имел теорию или объяснение того, почему мы можем получить новое знание или понимание, размышляя над нашими собственными идеями... Но современное использование интуиции в философии редко подкрепляется таким обоснованием. Уже этого вполне достаточно, чтобы такого рода апелляции к интуиции выглядели в высшей степени подозрительно» [8. С. 289].

Ни для никого не было секретом, против кого направлено это обвинение. Соперничество Крипке и Хинтикки было достаточно на слуху. Однако у Хинтикки были основания для такой критики, потому что апелляция к интуиции требует серьезного подкрепления интересными следствиями более технического порядка.

Но, как известно, этого не произошло, и больше того, интуиция подвела самого Крипке: его интерпретация Витгенштейна в работе «Витгенштейн о правилах и индивидуальном языке» большинством специалистов посчиталась ошибочной, что явилось шоком для звезды аналитической философии [9]. В каком же случае опора на интуицию является все-таки оправданной? И откуда взялось в аналитической философии стремление апеллировать не к анализу, а к интуиции? Хинтикка раскрывает «генезис» этой тенденции, продолжая разговор об угрозах аналитической философии со стороны этой тенденции.

Методологически неподкованные философы начали в 1960-х гг. имитировать Хомского, или скорее имитировать то, что они приняли за методологию Хомского. Эта методология воспринималась как существенное полагание на интуицию компетентного говорящего по поводу грамматически различных цепочек символов. Иногда задача грамматики характеризовалась как регламентация таких интуиций. Чего с самого начала не понимали философы, имитирующие Хомского, так это того, что он был тайным картезианцем, который за собой имел скрытое подкрепление своей апелляции к интуиции, которая, по крайней мере, удовлетворяла его. Увы, огромное число философов, которые в наши дни взывают к интуиции, не являются картезианцами и не имеют никакой другой теоретической поддержки для своей апелляции к интуиции. Поэтому они не предлагают никаких резонов в пользу того, почему мы должны доверять любому их заключению, которое прямо или косвенно основывается на апелляции к интуиции [8. С. 289].

В конечном счете по прошествии некоторого времени первоначальный энтузиазм, связанный с использованием Крипке «аргументации от интуиции», пошел на спад, потому что стало ясно, что опора на до-философские представления при формировании философских теорий несовместима с задачей, которую ставит перед собой аналитическое движение: согласно Куайну, экспликация есть элиминация, и если речь идет об экспликации дотеоретических понятий, то необходима их элиминация, которая исключает возврат к понятию, которое требует экспликации.

В этом смысле предложенная краткая история неприятия, возрождения и дальнейшего неприятия в аналитической философии аристотелевского эссенциализма представляет собой изменение концепции нормативности как неко- 
торого рода предписания, что можно там делать, а что нельзя. Неизбежно соотнесение изменения норм с переходом от одной парадигмы к другой. Но на наш взгляд, было бы естественным считать изменение норм процессом в рамках одной парадигмы, процессом в рамках нормального периода развития науки. Однако и при этом исследование такого процесса является важным для понимания структуры философского мышления.

\section{Литература}

1. Russell B. My Philosophical Development. London : Unwin Books, 1975.

2. The Linguistic Turn / ed. R. Rorty. Chicago : Chicago University Press, 1992.

3. Куайн У. Референция и модальность // Куайн У. С логической точки зрения / пер. В. Ладова и В. Суровцева. М. : Канон + , 2010. С. 200-228.

4. Куайн У. Две догмы эмпиризма // Куайн У. С логической точки зрения / пер. В. Ладова и В. Суровцева. М. : Канон+, 2010. С. 45-80.

5. Kripke S. Naming and Necessity. Cambridge : Harvard University Press, 1980.

6. Rorty R. How Many Grains make a Heap? // London Review of Books. 1980. Vol. 27, № 2. P. $12-13$.

7. Rorty R. Kripke vs Kant // London Review of Books. 1980. Vol. 2, № 17. P. 4-5.

8. Хинтикка Я. Кто там готов убить аналитическую философию? // Целищев В. Философский переписчик : переводы и размышления. Новосибирск : Омега-Пресс, 2014. С. 283-292.

9. Бейкер Г.П., Хакер П.М.С. Скептицизм, правила и язык / пер. В. Суровцева и В. Ладова. М. : Канон+, 2008.

Oxana I. Tselishcheva, Institute of Philosophy and Law, Siberian Branch of the Russian Academy of Sciences (Novosibirsk, Russian Federation).

E-mail: oxanatse@gmail.com

Vestnik Tomskogo gosudarstvennogo universiteta. Filosofiya. Sotsiologiya. Politologiya-Tomsk State University Journal of Philosophy, Sociology and Political Science. 2019. 49. pp. 51-59.

DOI: $10.17223 / 1998863 X / 49 / 6$

A CONFLICT OF NORMS IN PHILOSOPHICAL THINKING: THE CASE OF ANALYTIC PHILOSOPHY

Keywords: norm; paradigm; essentialism; metaphysics; Hintikka; Quine; Kripke; Rorty.

The article considers the problem of the conflict of norms in philosophical thinking within the framework of one paradigm. The subject of analysis is the styles of thinking in modern analytic philosophy in the treatment of the thesis of Aristotelian essentialism, a doctrine about necessary and contingent properties for objects. The conflict between the anti-metaphysical treatment of essentialism by Willard Quine and the revival of metaphysics of essentialism by Saul Kripke is investigated. The two approaches are compared within the framework of one paradigm of analytic philosophy on the basis of Quine's objections to quantifier modal logic and the admissibility of this logic in the concept of naming by Kripke. It is shown that Quine adopts normative guidelines within the framework of Russell's thesis "logic is the essence of philosophy", while Kripke's normative guidelines are based on recognizing the importance of pre-theoretical thinking inherent in the intuition of an ordinary person. The development of Kripke's new naming theory results in a revision of a significant number of traditional concepts, among which the justification for a priori necessary assertions stands out. Two ways of assessing the conflict of norms in analytic philosophy are considered. The first, belonging to Jaakko Hintikka, a prominent representative of the analytical trend, rejects the idea of the importance of pretheoretical thinking not explicated by logic. Hintikka believes that the refusal to use the logical apparatus when interpreting philosophical theses speaks of the weakness of the position of Kripke, who is known as the author of important logical ideas. The second, belonging to Richard Rorty, a prominent opponent of the analytical school, is based on the insignificance of addressing universal human intuition for philosophy. Rorty's position is motivated by the total criticism of the paradigm of analytic philosophy, while Hintikka's position is motivated by criticism of the norm of philosophical thinking within the framework of one paradigm. The article concludes that the history of rejection and revival in the analytic philosophy of Aristotelian essentialism is a change in the concept of normativity as a kind of a prescription of what can be done and what cannot be done there. As a consequence, the change of norms with the transition from one paradigm to another is inevitable. A view is suggested that it would 
be natural to regard the change in norms as a process within the framework of one paradigm, that is, a process within the framework of the normal (according to Thomas Kuhn) period of the development of science.

\section{References}

1. Russell, B. (1975) My Philosophical Development. London: Unwin Books.

2. Rorty, R. (1992) The Linguistic Turn. Chicago: Chicago University Press.

3. Quine, W. (2010) S logicheskoy tochki zreniya [From a Logical Point of View]. Translated from English by V. Ladov, V. Surovtsev. Moscow: Kanon+. pp. 200-228.

4. Quine, W. (2010) S logicheskoy tochki zreniya [From a Logical Point of View]. Translated from English by V. Ladov, V. Surovtsev. Moscow: Kanon+. pp. 45-80.

5. Kripke, S. (1980) Naming and Necessity. Cambridge: Harvard University Press.

6. Rorty, R. (1980a) How Many Grains make a Heap? London Review of Books. 27(2). pp. 12-13.

7. Rorty, R. (1980b) Kripke vs Kant. London Review of Books. 2(17). pp. 4-5.

8. Hintikka, J. (2014) Kto tam gotov ubit' analiticheskuyu filosofiyu? [Who is there ready to kill analytical philosophy?]. In: Tselishchev, V. (ed.) Filosofskiy perepischik: perevody i razmyshleniya [Philosophical copyist: translations and reflections]. Novosibirsk: Omega-Press. pp. 283-292.

9. Baker, G.P. \& Hacker, P.M.S. (2008) Skeptitsizm, pravila i yazyk [Skepticism, rules and language]. Translated from English by V. Surovtsev, V. Ladov. Moscow: Kanon+. 